\title{
Iron Deficiency Anemia: A Probable Risk Factor for First Episode of Simple Febrile Seizure
}

\author{
Dr. Syama Prasad Sit ${ }^{1}$, Dr. Swarupananda Maiti ${ }^{2}$, Dr. Mani Kant ${ }^{3}$, \\ Dr. Sekhar Mandal ${ }^{4}$, Dr. Achinta Mandal ${ }^{5}$ \\ ${ }^{1}$ Assistant Professor, Dept. Of Pediatrics, B.S.Medical College, Bankura, West Bengal \\ ${ }^{2}$ RMO cum Clinical Tutor, Dept. Of Pediatrics, B.S.Medical College, Bankura, West Bengal \\ ${ }^{3}$ PGT(MD); Dept. Of Pediatrics, B.S.Medical College, Bankura, West Bengal \\ ${ }^{4}$ PGT (MD); Dept. Of Pharmacology; B.S.Medical College, Bankura, West Bengal \\ ${ }^{5}$ Senior Resident; Dept. Of Pediatrics, B.S.Medical College, Bankura, West Bengal
}

\begin{abstract}
Objective: To study the role of iron deficiency as a risk factor for Simple febrile seizure.

Methods: This case-control study evaluated 50 children aged 6-60 months with first episode of simple febrile seizure (cases) and 50 age and sex matched children with febrile illness but without convulsion (controls) from the Pediatric ward of a peripheral state medical college\& hospital. Iron deficiency anemia was assessed in all participants by measuring Hemoglobin concentration (Hb \%), Mean corpuscular volume (MCV), Mean corpuscular hemoglobin $(\mathrm{MCH})$ and serum ferritin level.

Results: The mean serum ferritin level $(\mu g / L)$ was significantly lower in cases (24.81 \pm 9.04$)$ as compared to controls(47.29 \pm 8.33$)$ with $P<0.001$; patients with febrile seizure were 6.303 times more likely to have iron deficiency anemia compared to controls.

Conclusions: Findings suggest that a considerable percentage of children having first episode of simple febrile seizure suffer from iron-deficiency anemia and it can serve as a reinforcing factor for the febrile seizure in children.
\end{abstract}

Keywords: iron deficiency, anemia, serum ferritin, febrile seizure

\section{Introduction}

Febrile seizure is defined as "an epileptic seizure ... occurring in childhood after age 1 month, associated with a febrile illness not caused by an infection of the CNS, without previous neonatal seizures or a previous unprovoked seizure, and not meeting criteria for other acute symptomatic seizures" [1]. Febrile seizure is the most common convulsive disorder in children which strikes $2 \%$ to $5 \%$ of children between 6 to 60 months of age [2]. Because of its association with later epilepsy, various studies have attempted to identify the risk factors $[3,4]$.

Iron is needed for metabolism of several neurotransmitters and for myelination. In India $70 \%$ of children between 6-59 months are anemic [5] with more than half attributed to iron deficiency anemia (IDA) which overlaps with the peak incidence of simple febrile convulsion i.e 14-18 months.

Pisacane et al. [6] reported that low iron level is associated with febrile seizure in children below 2years whereas Kobrinsky et al. [7] reported that iron deficiency raises the threshold for seizures. Considering the contrasting results the present study was conducted to compare the iron deficiency anemia in the simple febrile seizure children to those in the febrile patients without convulsion.

\section{Materials \& Methods}

A case-control study was conducted from June 2015 to November 2015 in pediatric department of Bankura Sammilani Medical College, West Bengal. Fifty consecutive children aged 6 months to 5 years, admitted to the Pediatric ward with first episode of simple febrile seizure were enrolled as cases. Simple febrile seizures were defined as primary generalized seizures that lasted for less than 15 minutes and did not recur within 24 hours [8]. Children with previous febrile/ afebrile seizures, central nervous system infections, chronic neurodevelopmental problem, hematological problems or on iron therapy were excluded. A control group $(\mathrm{n}=50)$ was selected from age and sex matched children admitted with febrile illness (fever duration < 3days) including respiratory infections or acute gastroenteritis but without seizures and without iron supplements. After informed consent, detailed history was taken and physical examination was done. Estimation of hemoglobin 
$(\mathrm{Hb})$, mean corpuscular volume (MCV), mean corpuscular hemoglobin (MCH) (by automated hematology analyzer) and serum ferritin (Microwell Elisa) was done in all participants. Iron deficiency anemia was defined as hemoglobin $<11 \mathrm{~g} / \mathrm{dL}, \mathrm{MCV}<70 \mathrm{fl}, \mathrm{MCH}<27 \mathrm{pg}$ and serum ferritin $<25-50 \mu \mathrm{g} / \mathrm{dL}[9,10]$. Cases and Controls were compared in respect of age, temperature at admission, anthropometric variables, $\mathrm{Hb} \%, \mathrm{MCV}$, $\mathrm{MCH}$ and serum ferritin both as continuous and as dichotomous variables. Microsoft Office Excel was used for data entry and IBM SSPS version 22 was used for statistical analysis of data.

\section{Results}

Over a period of 6 months, 100 children aged 6 months to 5 years fulfilling the inclusion criteria, were considered for the study. Demographic data and hematological parameters of cases and controls are depicted in Table 1. Majority of children with first febrile seizures $(72 \%)$ were below the age of two years. Mean age of cases were 19 months. $62 \%$ of them were females with female to male ratio being 1.6:1. 32 out of 50 cases had iron deficiency anemia (64\%), where as 11 out of 50 controls were found to have iron deficiency anemia (22\%) with an odd's ratio of 6.3 (Fig.1). The difference in relation to iron deficiency anemia among the two groups was significant $(\mathrm{P}<0.05)$.

Serum ferritin level was also significantly lower in cases (24.81 \pm 9.04$)$ than control group (47.29 \pm 8.33$)$ with $\mathrm{P}$ value $<0.002$. Frequency of iron deficiency anemia with respect to cause of fever among cases \& controls are depicted in Table 2. Upper respiratory tract infection was the most common cause of fever in $54 \%$ cases followed by gastroenteritis, viral fever, urinary tract infection and dengue in that order.

\section{Figure and Tables}

Table 1: Demographic data and hematological parameters of cases \& controls

\begin{tabular}{|l|l|l|l|}
\hline Parameters & Cases(50) & Controls(50) & P-value \\
\hline Age(in months) & $19.18 \pm 8.04$ & $18.56 \pm 7.42$ & 0.69 \\
\hline Temp. at admission $\left(\right.$ in $\left.^{\circ} \mathrm{C}\right)$ & $38.52 \pm 0.22$ & $38.61 \pm 0.23$ & 0.06 \\
\hline Height $(\mathrm{cm})$. & $81.68 \pm 7.09$ & $82.23 \pm 7.06$ & 0.69 \\
\hline Weight $(\mathrm{kg})$. & $10.87 \pm 1.77$ & $11.28 \pm 1.75$ & 0.25 \\
\hline $\mathrm{Hb}(\mathrm{g} / \mathrm{dl})$ & $10.42 \pm 0.83$ & $11.27 \pm 0.94$ & $<0.01$ \\
\hline $\mathrm{MCV}(\mathrm{fl})$ & $70.02 \pm 5.75$ & $83.20 \pm 5.08$ & $<0.01$ \\
\hline $\mathrm{MCH}(\mathrm{pg})$ & $20.36 \pm 2.33$ & $26.64 \pm 2.82$ & $<0.01$ \\
\hline Serum ferritin $(\mu \mathrm{g} / \mathrm{l})$ & $24.81 \pm 9.04$ & $47.29 \pm 8.33$ & $<0.01$ \\
\hline
\end{tabular}

Able 2. Frequency of iron deficiency anaemia with respect to cause of fever among cases \& controls

\begin{tabular}{|c|c|c|c|c|}
\hline \multicolumn{2}{|l|}{$\begin{array}{l}\text { Cause of fever } \\
\text { cases }\end{array}$} & \multirow{2}{*}{$\begin{array}{l}\text { Iron deficiency } \\
\text { anemia }\end{array}$} & \multirow{2}{*}{$\begin{array}{l}\text { No.of controls } \\
25(50 \%) \\
\end{array}$} & \multirow{2}{*}{$\begin{array}{l}\text { Iron deficiency anemia } \\
2(18.18 \%) \\
\end{array}$} \\
\hline URTI & $27(54 \%)$ & & & \\
\hline Gastroenteritis & $10(20 \%)$ & $9(40 \%)$ & $12(24 \%)$ & $7(63.63 \%)$ \\
\hline Viral fever & $7(14 \%)$ & $3(42.85 \%)$ & $8(16 \%)$ & 0 \\
\hline UTI & $4(8 \%)$ & $2(50 \%)$ & $4(8 \%)$ & $1(9.09 \%)$ \\
\hline Dengue fever & $2(4 \%)$ & $1(50 \%)$ & $1(2 \%)$ & $1(9.09 \%)$ \\
\hline Total & 50 & 32 & 50 & 11 \\
\hline
\end{tabular}

Figure 1: Iron Deficiency Anemia among cases \& controls with a odd's ratio of 6.303

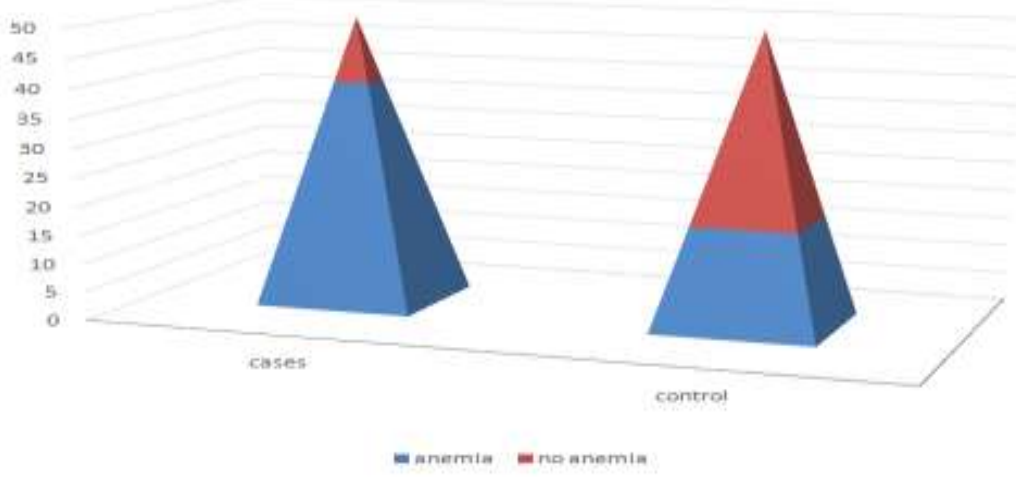




\section{Discussion}

Iron deficiency was found to be a significant risk factor for first episode of simple febrile seizures in our study, the risk becomes nearly six times (odds -6.303 ; $95 \%$ CI of 4.197-9.466) for simple febrile seizures in cases as compared to control group.

In the case-control study done by Pisacane et al. [5] with 146 cases and 293 control, with age of 6-24 months, reported a significantly higher rate of iron deficiency anemia among children with first febrile seizure than control (odd's ratio=3.3, 95\% CI of 1.7-6.5). In the study done by Daoud et al. [11] mean plasma ferritin level was significantly lower in the cases $(29.5 \mu \mathrm{g} / \mathrm{l})$ than in the controls $(53.3 \mu \mathrm{g} / \mathrm{l})(\mathrm{P}=0.001)$. Others measures of iron status were also lower among first febrile seizures patients, but the difference didn't reach statistical significance. Study done by Kumari et al. [12] found highly significant association between iron deficiency and simple febrile seizures. Crude odds ratio was 5.34 (CI 3.27- 8.73, $P<0.001$ ) and adjusted odds ratio in the logistic regression analysis was 4.5 (CI 2.69- 7.53, $P<0.001$ ). Similar observations were made in a previous study by Vaswani et al. [13]. The mean serum ferritin level was significantly low in children with first febrile seizures $(31.9 \mu \mathrm{g} / \mathrm{l})$ as compared to controls $(53.9 \mu \mathrm{g} / \mathrm{l})(\mathrm{P}=0.003)$. However, no significant difference was noted in the mean hemoglobin values of cases $(9.4 \pm 1.2 \mathrm{~g} / \mathrm{dL})$ and controls $(9.5 \pm 1.0 \mathrm{~g} / \mathrm{dL})$ or in the mean value of $\mathrm{MCV}(\mathrm{P}=0.89)$ and $\mathrm{MCH}(\mathrm{P}=0.71)$. In our study, iron deficiency was diagnosed by $\mathrm{Hb}, \mathrm{MCV}, \mathrm{MCH}$ and serum ferritin; all four parameters were significantly reduced among cases compared to controls.

Our study has some limitations. As it was a hospital based study actual data may vary in a community setting. Iron deficiency and convulsion may be seen in lead poisoning but lead level was not determined in our study participants.

\section{Conclusion}

Children with first episode of simple febrile seizures are almost six times likely to have iron deficiency anemia as compared to children with febrile illness without seizures. Iron deficiency anemia can be considered as a modifiable risk factor for simple febrile seizures in children between 6 months to 5 years. Early detection and timely correction of iron deficiency may help in preventing simple febrile seizures in children but larger studies are needed before routinely recommending iron in simple febrile seizures.

\section{References}

[1]. Commission on Epidemiology and Prognosis, International League Against Epilepsy. Guidelines for epidemiological studies on epilepsy. Epilepsia 1993; 34:592-96.

[2]. Berg AT. Febrile seizures and epilepsy: the contribution of epidemiology. Paediatr Perinatal Epidemiol 1992; 6:145-52.

[3]. Nelson KB, Ellenberg JH. Prenatal and perinatal antecedents of febrile seizures. Ann Neurol 1990; 27:127-31.

[4]. Berg AT, Shinnar S, Shaprio ED, et al. Risk factors for a first febrile seizure: a matched case-control study. Epilepsia 1995; 36:33441.

[5]. National Family Health Survey-3. Mumbai: IIPS; 2006. From: http://www.nfhsindia.org /data/India/ indch7.pdf. Accessed on December 10, 2015 .

[6]. Pisacane A, Sansor R, Impagliazzo N, et al. Iron deficiency anemia and febrile convulsion: case control study in children under 2 years. BMJ 1996; 313(7053):343.

[7]. Kobrinsky NL, Yager JY, Cheang MS, et al. Does iron deficiency raise the seizure threshold? J Child Neurol 1995; 10:105-9.

[8]. Nelson KB, Ellenberg JH. Predictors of epilepsy in children who have experienced febrile seizures. N Engl J Med 1976; 295(19):1029-33.

[9]. De Gruchy GC. Clinical Hematology in Medical Practice, 5th ed. Victoria: Blackwell Science Ltd; 2004.

[10]. Dallman PR, Yip R, Oski FA. Iron deficiency and related nutritional anemias. In: Nathan DG, Oski FA, editors. Hematology of Infancy and Childhood. 4th ed. Mexico: Saunders; 1993. p. 413- 50.

[11]. Daoud AS, Batieha A, Ekteish A, Gharaibeh N, Ajlouni S, Hijazi S. Iron status: a possible risk factor for first febrile seizures. Epilepsia 2002; 43:740-43.

[12]. Kumari PL, Nair MK, Nair SM, Kailas L, Geetha S. Iron deficiency as a risk factor for simple febrile seizures--a case control study. Indian Pediatr 2012; 49(1): 17-19.

[13]. Vaswani RK, Dharaskar PG, Kulkarni S, Ghosh K. Iron deficiency as a risk factor for first febrile seizure. Indian Pediatr 2010; 47(5): 437-39 